\title{
Climate Change: Impacts on Insurers and How They Can Help With Adaptation and Mitigation
}

\author{
Trevor Maynard \\ Emerging Risks, Lloyd's, Lloyd's Exposure Management, One Lime Street, London EC3M 7HA, U.K. \\ E-mail: Trevor.Maynard@lloyds.com
}

Climate change is already affecting the global insurance industry. These changes are often seen as being negative, although opportunities also exist. Other areas of insurance coverage may also be affected in addition to property damage. The potential for third-party liability claims from climate change is less well understood but has even greater potential to affect the industry. Financial assets held to meet claims and provide a capital buffer may also be affected. Therefore the balance sheet of an insurer may be damaged from all sides. Insurers cannot force policyholders to mitigate $\mathrm{CO}_{2}$ emissions, but they can give them a choice and a number of them are already offering such policies. They can also take steps to reduce their own carbon emissions. Insurance is adaptation; there are a surprisingly large number of small to medium companies that do not have catastrophe cover, so increasing insurance penetration of these markets would be an adaptive measure. Insurers will continue to lobby governments for appropriate weather defences to keep areas insurable for as long as possible. Non-traditional forms of insurance are available (such as those based on weather indices with parametric triggers) and it may be possible to continue to offer these for longer than traditional insurance. They do bring basics risk with them, and therefore possibly reputational risk to the industry. Insurers can only pool risk; we cannot insure our way out of this problem, but we can help to spread the impacts where possible.

The Geneva Papers (2008) 33, 140-146. doi:10.1057/palgrave.gpp.2510154

Keywords: climate change; insurance; adaptation; mitigation; socially responsible investment; risk management

\section{Impacts on the (re-)insurance industry}

Climate change is already affecting the global insurance industry. These changes are often seen as being negative, although opportunities also exist. There are clear trends in past climate data that have translated into trends in insurance claims. Sea levels have risen, leading to greater storm surges, causing more claims (e.g., Katrina). Forest fires last for longer and are more frequent, leading to more property damage and more insurance claims. At Lloyd's, we have increased our disaster planning scenarios from USD 70bn events in 2005 to USD 108bn events in 2007, reflecting changes in our perception of the risk, demographic changes, and the changing dynamic of the built environment.

Other areas of insurance coverage may also be affected in addition to property damage. The potential for third-party liability claims from climate change is less well understood but has even greater potential to affect the industry, especially when policies have the potential for claims arising from past years of cover. The huge 
economic and social impact of climate change will inevitably lead to accusations, claims and lawsuits over attribution of causation, which will impact on liability classes. Directors and officers could be sued where it can be shown that they have not managed their company's contribution to, or exposure to the effects of, climate change. The construction industry can contribute significantly to weather-related risks through bad planning and inappropriate construction techniques. The list of professions with potential legal obligations who may be sued is extensive and includes architects, consulting engineers, designers and surveyors. Flooding often leads to very significant pollution, which can often be traced back to a source, leaving the door open for legal action.

Insurance companies hold reserves to meet the expected value of future claims and additional capital is held against unexpected events. Financial assets are held to back these reserves and capital. For general insurers, reserves are typically backed by a mixture of government and corporate-fixed interest securities. However, in many cases at least part of an insurer's capital is invested in equities and possibly property. Both these latter classes may be adversely affected by climate change. Take property investments; some argue that the costs of retrofitting these (with air conditioning for example) is not yet fully factored into their market value, and this leads to a risk of sudden shocks in values as markets realise their error. Similarly some sectors of the equity markets will be affected, some positively, some negatively; this could be due to adverse impacts on profitability (if climate change leads to a reduction in the operational efficiency of some machinery for example). Again some argue that such factors are not yet factored fully into market prices and so sudden shocks in value are possible. The projected lifetime for a building may be impaired or the value affected if the building lies within an existing floodplain.

We have seen above that liabilities of an insurer are likely to be affected by climate change in a number of ways. Unless terms and conditions or insurance coverage change, capital requirements are likely to increase as the probability of extreme events increase. We see that the assets (the other side of the balance sheet) are also likely to be adversely affected, falling in value possibly at the same time that the liabilities and capital requirements are rising. The balance sheet is vulnerable from all sides.

An insurer's share price is made up from more than its net assets. The value of future new business is also a major component of an insurer's market worth. This is strongly linked to reputation and this too could be damaged, or enhanced, by climate change. The demonstration of responsible risk management is a minimum expectation for most stakeholders.

Insurers pool risk. They work on the premise that insurable risks can be:

- quantifiable (i.e. that the risk is largely constant over the period of insurance and well understood);

- diversifiable (that one type of risk can be offset against another, for example that household and motor books are largely independent);

- fortuitous (may or may not happen);

- economically priced (the policyholder can afford to pay). 
Risks can cease to be insurable when any of these requirements cease to be true. Climate change can affect all of these. Our understanding of risk is reduced when conditions are changing; many regions around the world are affected at the same time, reducing the amount of diversification; climate change will happen, and in some regions extreme events may become annual occurrences; the level of losses may increase to such an extent that insurance premiums become higher than policyholders are prepared to pay.

In these circumstances, insurers must review whether insurance coverage can remain unchanged. If not, then terms and conditions are revised and, in extremis, cover is removed altogether. These are not the actions of an uncaring industry, but an industry acting prudently to maintain solvency and shareholder returns via prudent risk management and risk adequate pricing strategies. However, while such actions may be economically necessary they may lead to adverse impacts on our reputation, possibly leading to negative impacts on share prices.

So the insurance industry is very interested in climate change because it can damage all sides of its balance sheet, because its reputation may be affected, but also because it has the opportunity to be a major force for good to help society, both the business world and the public, to better manage risk.

We cannot insure our way out of the problem. Reinsurers and alternative capital market providers will not accept risk on terms that are not commercially viable. Ultimately actions for mitigation are crucial to tempering the effects of the changes to come. Adaptation too is vital, as some climate change is now bound to happen and losses can be kept to a minimum by careful action. The insurance industry can actively play its part in mitigation and encouraging others to do so; it can also be a force to encourage appropriate adaptation. The remainder of this article focuses on these two issues.

\section{Mitigation - how the industry can help}

It has been suggested that insurers should force mitigation actions onto their policyholders, for example, by including compulsory carbon offsetting costs in motor policies, or not offering insurance for a building project unless it is built with green materials. The insurance industry cannot do this. To do so would be to elevate the role of insurance to one of taxation and that is the role of governments. It must be understood that the global insurance industry is a highly competitive market. These behaviours sometimes (but not always) increase the cost of insurance and many policyholders choose their insurance on the basis of cost. But there are many steps an insurer can take to help with mitigation of climate change.

First, we can get our own houses in order. Many insurance companies are doing this. Some are considering carbon neutrality as an aim. Others are looking at energy efficiency of their properties and how to improve this (e.g., in 2006 Lloyd's commissioned a review of its London Office by the Carbon Trust and are currently endeavouring to act on their recommendations). Insurers have huge purchasing power. After a claim we are involved with rebuilding, and also removal of waste. We can ensure that this is done in a sustainable way. If waste has to be removed, can it be recycled? If not, can it be disposed of in an environmentally 
friendly way? If new products have to be used are low carbon products available that could be chosen in place of others? Can we encourage our policyholders to choose these options?

There are already policies on the market that allow policyholders to offset their travel at the point of purchasing motor insurance (e.g., the Cooperative Insurance offers this). The pay-as-you-drive policies that have recently become available, some argue, already help with mitigation as they encourage less driving.

As already noted, many insurers are large investors in equity markets; in other words they are shareholders and can help with mitigation by making their wishes clear. They have two strategies available to them here: first they can avoid investing in companies that are major carbon dioxide emitters, this is often called Socially Responsible Investing; second, they can use their voting rights at AGMs and engage with the boards of companies in which they invest to act in a sustainable way. Some argue that the second approach will ultimately be more successful as it is the major emitters that need to change most.

Many non-insurance companies are actively investing in developments and research in areas designed to mitigate climate change. Examples of these are: geo-thermal energy; wind-farms; solar energy; hydro energy; carbon sequestration; hybrid vehicles; biomass. All of these developments will also lead to developing risks that will require insurance solutions. Insurers can consider new products directly involved in the carbon markets. Take the Clean Development Mechanism (CDM) set up under the Kyoto protocol to enable countries to invest in greenhouse gas reduction projects in other countries and use this to offset their own carbon footprint. Such CDM projects run the risk that they will not deliver the greenhouse gas reduction they were expected to; and if CDM credits have been sold there is a liability to deliver. This can discourage capital providers supporting such products. Swiss Re has teamed up with RNK capital to provide insurance against this risk, a good example of using our core industry skill to promote mitigation.

\section{Adaptation}

Surprisingly, a large number of smaller companies do not have insurance against catastrophic weather loss. The UNEP FI report Insuring for Sustainability quotes figures from AXA, which suggest that over 50 per cent of businesses with less than $£ 50 \mathrm{k}$ turnover are not insured against such events; for companies 10 times that size some 25 per cent are still not insured. Yet when small businesses that had been affected by a severe weather event were asked to rank the help they received from a range of choices (such as emergency services, local government, etc.) insurance comes out top. Simply increasing the proportion of businesses insured will help with adaptation. We can become a lot more efficient with our existing insurance systems without even needing to change them.

In 2003, the ABI issued a Statement of Principles on the Provision of Flood Insurance setting out the U.K. non-life insurance industry's commitment to maintain provision of flood cover (for areas with less than 1 in 75-year flood risk, ABI members will provide flood cover as standard but with premiums differentiated to reflect the risk) but also the actions it expected of the U.K. Government (e.g., the reform of the 
land-use planning system to ensure sustainability). This is an example of the non-life insurance industry engaging with local and national government in the area of adaptation.

The non-life insurance industry needs to convince its policyholders that we are part of the solution to climate change, not part of the problem. Good communication and education is key here. Some insurers already have links to useful resources from their websites; they could go much further. Some companies are considering early warning systems to policyholders as they learn of incoming natural hazards and they can send out emails and text messages alerting policyholders to give them time to prepare their properties and reduce claims costs. Policyholders can be encouraged to adapt their properties to reduce risk. The non-life insurance industry can work with policyholders to encourage this behaviour and reflect it in premiums.

After a catastrophe it is important to rebuild in such a way as to reduce the costs of loss in future events. In the U.K., insurers are very supportive of this idea and have, in partnership with the National Flood Forum, produced literature for policyholders on how to rebuild sustainably after a flood. In many cases the costs are similar. If they are more expensive, a small loan may be required. The Association of British Insurers has worked with the Council of Mortgage Lenders which has agreed to look favourably on requests for additional loans to pay for such work, an example of different businesses cooperating with one another and their customers.

Insurers are already involved in a number of innovative initiatives, often in partnership with governments and non-governmental aid agencies in developing countries, designed to assist with adaptation to climate-related impacts. Examples include:

- The Caribbean Catastrophe Risk Insurance Facility (CCRIF), which was launched in 2006 (following the impact of Hurricane Ivan 2 years earlier), through the cooperation of the World Bank and the Heads of Government of the Caribbean Community. It provides participating governments with immediate liquidity if hit by a natural disaster, until other sources of financing become available and essentially allows Caribbean countries exposed to natural disasters to pool their risk in order to lower the cost of coverage. The innovative use of a parametric trigger is interesting here but also brings basis risk and the possibility for damage to our reputations if payouts do not match damages suffered.

- A cooperation between the World Food Programme and Axa Re, funded by the Ethiopian government and a small group of donors including the U.S. Government, which used weather derivatives to cover rural families against drought.

We should not support actions that are economically unjustifiable; we should lobby hard when decisions are being taken that do not properly take account of the risk and we should resist cross-subsidy among new infrastructure vehemently. The case for existing property is different; here we have a responsibility to maintain a level of insurance for as long as possible; but we can expect policyholders to take action to reduce their risk and again we should resist regulators and governments that are motivated only by the voting powers of such policyholders. Adequate research and its publication are our best defence in these situations. 
We clearly need to encourage and carry out research into this risk so we can protect our shareholders' capital and at the same time help society to manage the risks. As an industry, we need to capture better data; only with more accurate data in terms of location, construction of property, the use to which they are put, the building standards that they satisfy and other relevant factors, can we accurately access the risk.

\section{Conclusion}

The dynamics of climate change will influence the nature of risks across the globe and will inevitably affect the insurance industry as it helps society to manage risk. All aspects of an insurer's balance sheet, its liabilities, capital requirements and assets may be affected. The industry's reputation is also at risk and careful communication is required with policyholders, regulators and government. Insurers can be a positive force in encouraging adaptation and mitigation. The new Climate Wise ${ }^{1}$ initiative supported by many in the insurance industry is a step in the right direction. Much is already being done, still more is possible.

\section{Disclaimer}

The thoughts expressed in this note reflect those of the author and do not necessarily reflect those of Lloyd's.

\section{References and background reading}

ABI and National Flood Program, Repairing your home or business after a flood - how to limit damage and disruption in the future', taken from http://www.abi.org.uk/BookShop/ResearchReports/Flood per cent20Repairpercent20Docpercent201.pdf.

Climate Change Working Party - GIRO (2007) The implications of climate change on non life insurance, Climate Change Working Party - GIRO, London.

DFID (2004) 'Adaptation to climate change: Can insurance reduce the vulnerability of the poor?', from http://www.dfid.gov.uk/pubs/files/climatechange/8insurance.pdf.

F\&C Investments (2007) In the front line: The insurance industry's response to climate change Reo Research, http://www.fundworksinvestments.com/fn_filelibrary//file/co_gsi_Climate_Change_Insurance_Report. pdf.

Lecomte, E. and Mills, E. (2006) From risk to opportunity: How insurers can proactively and profitably manage climate change A CeresReport, Ceres, Boston (August).

UNEP FI (2007) Insuring for Sustainability - Why and How the Leaders are Doing it?, Geneva: UNEP FI http://www.unepfi.org/fileadmin/documents/insuring_for_sustainability.pdf.

\section{About the Author}

Trevor Maynard is Manager of Emerging risks at Lloyd's of London. He was the author of their first paper on climate change "Adapt or Bust" and editor of their third

\footnotetext{
${ }^{1}$ ClimateWise http://www.climatewise.org.uk/
} 
146

"Rapid Climate Change". Trevor has represented Lloyd's and the insurance industry on climate change matters on various occasions including recently speaking at the European Commission's "Green Week" on the subject of adaptation and the insurance industry. He attends sub-groups of the London Climate Change Partnership and United Nations Environment Program. Trevor is a Fellow of the Institute of Actuaries and chairs an actuarial climate change working party. He has degrees in pure mathematics from Warwick University. 